ISSN 1981-416X

Licenciado sob uma Licença Creative Commons

\title{
O paradoxo da educação física: uma reflexão crítica das perspectivas contraditórias na esfera escolar
}

The paradox of physical education: a critical reflection on the contradictory perspectives in the school area

El paradojo de la educación física: una reflexión crítica de las perspectivas contradictorias en el ámbito escolar

\section{Matheus Bernardo Silva*}

\section{Resumo}

Trata-se de uma pesquisa de cunho teórico-metodológico, cujo intuito foi constatar que o paradoxo da educação física escolar se aloja nas perspectivas díspares oriundas, por um lado, pelas ciências naturais e, por outro, pelas ciências humanas. Tal paradoxo é constituído, portanto, pelo colonialismo epistemológico que a educação física escolar se encontra atualmente. Em contrapartida e como alternativa de superação deste paradoxo, explicita-se a condição de a educação física escolar ser compreendida como uma modalidade de educação e, por conseguinte, estar balizada por uma ciência da e para $a$ educação; isto é, uma

*MBS: Doutor em Educação, e-mail: matheusbernardo25@gmail.com 
teoria da educação que tenha a prática pedagógica como ponto de partida e de chegada do processo educativo escolar.

Palavras-chave: Paradoxo da Educação Física Escolar. Epistemologia. Prática Pedagógica.

\begin{abstract}
This research has a theoretical-methodological approach and aimed at verifying the paradox of school physical education is based on the different perspectives, and they come from the natural sciences on the one hand, and on another, from the human sciences. Therefore, the paradox is constituted by the epistemological colonialism that physical education is inside nowadays. In contrast and an alternative to overcome this paradox, the circumstance that school physical education is understood a modality of education and consequently based on a science from and to the education is made explicit. In other words, it is a theory of education which has the pedagogical practice as starting and arrival point of the school education process.
\end{abstract}

Keywords: Paradox of School Physical Education. Epistemology. Pedagogical Practice.

\title{
Resumen
}

Esta investigación tiene abordaje teórico-metodológico, cuyo objetivo fue constatar que el paradojo de la educación física escolar se basa en perspectivas diferentes, de un lado venidas de las ciencias naturales, y de otro, de las ciencias humanas. Así, eso paradojo se hace por el colonialismo epistemológico que la educación física escolar se encuentra actualmente. En contrapartida y como alternativa para superar este paradojo, se hace explicita la condición de que la educación física escolar es comprendida como una modalidad de educación, y por consiguiente, se limita por una ciencia da y para la educación; es decir, una teoría de la educación que tenga la práctica pedagógica como punto de partida y de llegada del proceso educativo escolar.

Palabras clave: Paradojo de la Educación Física Escolar. Epistemología. Práctica Pedagógica. 


\section{Introdução}

Ao direcionar o olhar para a educação física, mais precisamente na esfera escolar, parece que estamos diante de uma aporia. Parece que estamos perante uma "[...] dificuldade de ordem racional, aparentemente sem saída" (FERREIRA, 2014, p. 55). Dito de outro modo, parece que estamos em uma condição de "[...] dificuldade inerente a um raciocínio, e não no de estado subjetivo de incerteza. É, portanto, a dúvida objetiva, a dificuldade efetiva de um raciocínio ou da conclusão a que leva um raciocínio" (ABBAGNANO, 2007, p. 84).

Esta aporia está em voga, principalmente desde meados da década de 1980, quando iniciou um movimento, no âmbito da educação física, questionando a aptidão física e o esporte moderno como objetos hegemônicos para esta área do conhecimento. Por conseguinte, começou a se questionar a fundamentação teórico-metodológica que apontava tais objetos como fios condutores para a educação física e, consequentemente, para a educação física escolar. Estava em voga a crítica aos aportes naturalistas, balizados nos princípios das ciências naturais. Em contrapartida, este movimento, conhecido como movimentos renovadores (COLETIVO DE AUTORES, 2014), procurou se embasar nas ciências humanas, a fim de problematizar e apresentar demandas para o campo da educação física e, em particular, na sua esfera escolar.

Fica estabelecida, a nosso ver, uma aporia no sentido de, a princípio, não encontrar uma possível saída para o que se concretizou, na área da educação física, como uma polaridade. Seguindo a análise de Saviani (2014, p. 86) sobre o significado de aporia em Aristóteles: “[...] ela [a aporia] se configura como um 'problema lógico, como um paradoxo nascido da existência de raciocínios igualmente coerentes e plausíveis que alcançam conclusões contrárias"”.

Portanto, estamos diante de um paradoxo da educação física. No recorte dado para este texto, estamos diante de um paradoxo da educação física escolar no tocante à fundamentação teórico-metodológica (epistemologia) e ao trabalho educativo (prática pedagógica). Destarte, 
procuramos aprofundar a discussão sobre a condição de impasse na educação física escolar, pois vigora um paradoxo no que se refere à sua base teórica e, por consequência, no seu aspecto pedagógico. Há, então, um paradoxo da sua natureza e, por consequência, da sua especificidade.

Referente à questão metodológica, tomamos a seguinte pergunta como indagação vetorial do exposto texto: quais as sustentações vigentes que legitimam o paradoxo da educação física escolar? Para tanto, optamos por realizar a exposição em três momentos: $a$ ) na explicitação de como ocorre o paradoxo da epistemologia da educação física, no qual impacta a legitimidade da sua natureza; $b$ ) na exposição da influência que o primeiro paradoxo efetiva na prática pedagógica, configurando, assim, o segundo paradoxo, que ocorre na especificidade da educação física escolar; c) na apresentação, ao identificar as sustentações de tais paradoxos, elementos que possam contribuir para a superação do dilema concretizado por meio de tais paradoxos.

\section{O paradoxo da epistemologia da educação física escolar: ciências naturais ou ciências humanas?}

Historicamente, a educação física escolar foi compreendida como uma área do conhecimento subjacente às ciências naturais. A especificidade do seu campo de atuação justificava-se, e ainda se justifica de certa maneira, por meio das orientações advindas das ciências naturais. Assim sendo, não há a possibilidade de estabelecer um objeto de conhecimento que seja específico da educação física escolar, pois ela é um instrumento utilizado por outras ciências que procuram, por sua vez, com a utilização desse instrumento, conferir, averiguar e confirmar hipóteses baseadas naquilo que lhe é específico.

A educação física escolar é compreendida como um meio a ser utilizado para que outras ciências, em especial, as ciências naturais, possam efetivar aproximações perante seus específicos objetos de estudo. Neste caso, é comum direcionar a especificidade da educação física escolar 
para a aptidão física como suposta contribuição para a promoção da saúde dos indivíduos. Ora, nota-se que a educação física escolar se restringe a promover determinadas atividades, ou melhor, práticas direcionadas para a realização de exercícios físicos.

A prática de exercícios físicos, promulgada pela educação física escolar como condição fulcral para a promoção da saúde, nada mais é do que ela tornando-se instrumento de determinadas ciências naturais, na tentativa de confirmar a tese de que, via exercício físico, consolida-se um estilo de vida ativo do indivíduo e, assim, contribui para a promoção da saúde. O ponto de vista vigente, neste caso, para pensar o trabalho educativo, está a partir das constatações das ciências naturais e, por consequência, como contribuição para sanar determinada demanda científica destas áreas do conhecimento.

Autores como, por exemplo, Guedes (1999), Guedes e Guedes (2001), Nahas (2013) e Costa, Garcia e Nahas (2012) defendem uma proposta de educação física direcionada para a proposição acima mencionada. Em Guedes (1999), a educação física para a saúde, nos moldes apenas biológicos e higienistas, exclui a possibilidade de dominar e encorajar, por parte do aluno, as atitudes de fato em prol da sua saúde. Isto porque não permite "[...] que novos conhecimentos sejam incorporados de forma integrada e duradoura em direção à auto independência em decisões quanto à adoção de um estilo de vida saudável" (GUEDES, 1999, s. p.). O autor argumenta que, para incidir no processo de conscientização e intervenção para um estilo de vida saudável do aluno, é necessário não somente o conhecimento biológico, mas também o domínio didático-pedagógico para a execução deste processo.

Para Guedes (1999), isto ocorre desde a influência médica até a esportiva na educação física, pois a educação para a saúde não era um objetivo a ser atingido de forma sistemática e efetiva. Tal objetivo se realiza apenas no plano teórico; porém, não se efetiva na prática. Em contraposição, o autor propõe que "[...] os programas de educação física escolar deverão preparar os educandos para um estilo de vida permanentemente ativo, em que as atividades físicas relacionadas com a saúde passam a fazer parte integrante do seu cotidiano ao longo de toda a vida" (GUEDES, 1999, s. p.). 
Em caráter similar, encontramos a proposta de Nahas (2013), para quem a função da educação física escolar transcorre como propulsora da aptidão física ou do incentivo da promoção de estilos de vida ativos. Estilo de vida ativo, nesta concepção, refere-se à realização regular de exercícios físicos. Em outras palavras, trata-se de sugestões a serem implementadas como um programa que incida no processo de conscientização e intervenção por meio do exercício físico, em proveito da aptidão física e da saúde.

Observa-se, aqui, que o raciocínio lógico dado para uma saída plausível sobre as questões epistemológicas da educação física escolar é deixá-la a serviço das necessidades oriundas das ciências naturais, pois, assim, haverá a possibilidade de legitimação, tanto da sua natureza quanto da sua especificidade (trabalho educativo). Logo, a saída plausível e coerente é a compreensão do indivíduo como detentor de um corpo ahistórico e acrítico, cuja finalidade da educação física escolar é introjetar, no aluno, a importância da realização de exercícios físicos na sua vida diária como um sinônimo de uma boa saúde. Este componente curricular reduz-se ao mecanismo instrumental, compactuando, por um lado, com uma formação restrita do aluno, no que diz respeito a suprimir a possibilidade de apropriação das máximas objetivações humanas e, por outro lado, propaga uma ideia equivocada sobre a relação entre educação física, exercício físico e saúde.

De outra maneira, em meados da década de 1980, um movimento no âmbito da educação física inicia os questionamentos sobre as repostas consolidadas referentes às questões específicas da educação física escolar, via os preceitos científicos validados pelas ciências naturais.

Como sabemos, a partir do final da década de 1970 e início da década de 1980, ocorreu um marcante movimento no contexto brasileiro, direcionado para a possibilidade de mudanças nas instituições sociais. $\mathrm{O}$ esgotamento daquilo que era intitulado como milagre econômico brasileiro e a tentativa de reorganização do movimento operário foram alguns precedentes para efetivar um movimento de reflexão e tentativa de mudança social, indo de encontro ao modo social vigente. No caso da educação física, pela primeira vez, se "[...] questionava 'teoricamente' sua histórica funcionalidade aos interesses das elites dominantes e inaugurava um movimento de 
engajamento com a luta pela mudança radical (na raiz) da sociedade capitalista" (HUNGARO, 2014, p. 137). Questionava-se, então, a provisoriedade das ciências naturais como motriz para a educação física escolar.

Urgiu um forte movimento que, de certo modo, resultou em uma polaridade no âmago da educação física escolar brasileira. Iniciou-se um processo de refletir sobre esta área do conhecimento e suas condições pedagógicas por meio das ciências humanas. Isto porque se advogava a ideia de que a educação física escolar deveria assumir preceitos que a fizesse contribuir com o desenvolvimento integral do aluno. Para isto, era necessário, de acordo com esta vertente, balizar-se nos aportes teóricos oriundos das diversas ciências humanas.

Neste sentido, a educação física escolar, primeiramente, foi um elemento no cerne de uma estratégia política, ou seja, em virtude da negação das demandas oriundas das ciências naturais para a educação física escolar. Portanto, via as ciências naturais, objetiva-se um aporte formativo em proveito da equalização social, da naturalização social e, por conseguinte, da naturalização do corpo humano. Em contrapartida, via as ciências humanas, admite-se a ideia de a educação física escolar ser compreendida por meio da categoria cultura.

Com efeito, a referência à categoria cultura tornou-se lugar comum para o movimento na educação física orientada pelas ciências humanas, tornando-a uma categoria basilar para o processo educativo na educação física escolar. Conforme interpretação de Bracht (2011, p. 101),

Uma das razões para utilizar o termo cultura é a de que ela força uma redefinição da relação da Educação Física com a Natureza e com seu conhecimento fundamentador. É preciso superar o "naturalismo" presente historicamente na nossa área. Tudo na nossa área era (em parte ainda é) considerado natural: o corpo é algo da natureza, as ciências que nos fundamentam são as da natureza, a própria existência e/ou necessidade da Educação Física é natural. Entender nosso saber como uma dimensão da cultura não elimina sua dimensão natural, mas a redimensiona e abre nossa área para outros saberes, outras ciências (outras interpretações) e amplia nossa visão dos saberes a serem tratados. 
Esta reflexão ocorre, portanto, em prol da compreensão das práticas corporais ${ }^{1}$ (termo comum a ser utilizado na área) no tocante à cultura, mais precisamente à cultura física, cultura do movimento, cultura corporal, cultura corporal de movimento, etc. Em outras palavras, torna-se comum atrelar ao termo cultura um determinado adjetivo para definir o objeto de conhecimento da educação física escolar.

Daolio (2007, p. 01), ao afirmar a relação inerente entre cultura e educação física, expõe que, após o forte domínio das ciências naturais (em específico a ciência biológica, na acepção do autor)

nas explicações sobre o corpo, a atividade física e o esporte moderno por parte da educação física, essa tarefa hoje parece estar dividida com os conhecimentos provindos de outras áreas, tais como a antropologia social, a sociologia, a história, a ciência política e outras.

Nota-se que ocorre uma contradição sobre a dimensão epistemológica da educação física escolar, significando que se consolida o paradoxo da epistemologia na educação física escolar. Esta segunda vertente apresenta uma compreensão coesa e plausível sobre a educação física escolar, que é oposta à compreensão da primeira vertente, oriunda das ciências naturais.

Nesta segunda vertente buscam-se elementos nas diversas ciências humanas para legitimar a natureza da educação física escolar no campo da cultura. Entretanto, ao mesmo tempo em que se afasta da primeira vertente (ciências naturais), esta (ciências humanas), contraditoriamente, se aproxima da anterior em um determinado aspecto. Ocorre um afastamento no sentido de extrapolar o referencial teórico das ciências naturais e evidenciar os condicionantes sociais. Porém, aproxima-se, porque também compreende a educação física escolar como um instrumento de outras ciências, mas agora vinculada às ciências humanas.

A educação física escolar passa a verificar, aferir e confirmar hipóteses das demandas que surgem pelos distintos objetos de conhecimento das ciências humanas. Logo, a educação física escolar passa, por

1 Conferir LAZZAROTTI FILHO et al. (2010). 
exemplo, a ser compreendida como o espaço de várias culturas; como momento no qual o aluno deverá, por conta própria, despertar os seus interesses; como momento que deverá estimular o aluno a aprender a aprender; etc. O que está no horizonte, de forma predominante, é o culturalismo, a lógica que compactua com a ideia de que a cultura é algo que ocorre de maneira espontânea e, por consequência, o indivíduo desenvolve-se de forma espontânea. Trata-se aquilo que é específico da educação física escolar via a espontaneidade, via um relativismo cultural.

Estamos frente a um paradoxo da educação física escolar: busca-se apresentar respostas sobre a natureza da educação física escolar por meio de certos raciocínios, pois apresentam justificativas e referencias plausíveis, coerentes e que chegam a conclusões opostas.

Este primeiro paradoxo incute elementos para a efetivação de um segundo paradoxo, também no campo da educação física escolar: o paradoxo da prática pedagógica em educação física. Ele advém do primeiro, pois, ao apresentar respostas contrárias sobre a natureza da educação física escolar, instituem-se respostas também contrárias sobre sua especificidade (o trabalho educativo, ou seja, a prática pedagógica). Vejamos, na sequência, como ocorre este paradoxo e suas implicações.

\section{O paradoxo da prática pedagógica em educação física: aptidão física ou espontaneísmo?}

Como consequência do primeiro paradoxo, perguntamos: qual a especificidade da educação física escolar? Podemos responder de duas maneiras, elucidados pelas distintas compreensões de educação física escolar acima citadas: primeiro, que o trabalho educativo (a prática pedagógica) deriva das orientações das ciências naturais, isto é, deve partir dos princípios consolidados nas ciências naturais; segundo, que o trabalho educativo (a prática pedagógica) deriva das orientações das ciências humanas, ou seja, deve partir dos princípios consolidados nestas ciências. 
Quanto às orientações advindas das ciências naturais, as questões pedagógicas são direcionadas para cumprir os objetivos estipulados pelas próprias ciências naturais. Significa que a maneira que desencadeará a prática pedagógica será para atingir as finalidades elencadas por tais ciências.

A prática pedagógica, neste sentido, não está como ponto inicial e final do processo educativo escolar. Contudo, a prática pedagógica em educação física torna-se um instrumento para as ciências naturais. O trato pedagógico a determinado objeto de conhecimento está subordinado às necessidades científicas que surgem nas ciências naturais.

Caso, à guisa de ilustração, conceba o sedentarismo como algo a ser trabalhado no âmbito da educação física, como disciplina escolar, tal temática será tratada a partir dos conceitos, princípios, procedimentos, e outros aspectos das ciências naturais. Por conseguinte, o que se constata é que o sedentarismo, neste caso, não é um problema pedagógico, uma temática posta pelo pressuposto da e para a educação (da e para a promoção humana), mas um problema submetido a partir da relevância que ele possui para determinadas ciências naturais.

É comum, então, consolidar planejamentos pedagógicos, planos de aulas e práticas pedagógicas, na educação física escolar, que assumem o prisma das ciências naturais, resumindo-a como apenas um aspecto instrumental. Torna-se vigente a aplicação e aferição de aptidões físicas dos alunos por meio de testes físicos validados por determinadas ciências naturais como, por exemplo, a cinesiologia, a biomecânica, a fisiologia, entre outros.

Em consequência, observa-se o predomínio de conteúdos técnicos e instrumentais presentes nas grades curriculares dos cursos de educação física e, como desdobramento, nas aulas de educação física nas escolas. Podemos conferir esta observação ao analisarmos o estudo de Nahas (2013) sobre a sua proposição para as especificações dos programas de ensino para a educação física escolar: a prática pedagógica em educação física, principalmente no Ensino Médio, deve enfatizar os conteúdos referentes ao exercício físico para a aptidão física que, consequentemente, incidirá na saúde do aluno. Portanto, nos primeiros anos escolares, a educação física deve trabalhar em proveito do desenvolvimento motor das 
crianças e incentivá-las a se identificarem com atividades recreativas ativas, deixando a aptidão física em um segundo plano da prática pedagógica. Assim, no Ensino Médio, priorizam-se os conteúdos sobre a atividade para a aptidão física em proveito da saúde.

Nesta lógica, o mesmo autor, em conjunto com outros autores, afirma que a educação física é um espaço privilegiado para a conscientização e efetivação da prática de exercícios físicos como sinônimo de um estilo de vida ativo e, portanto, saudável. Para tanto, deve-se dar enfoque em experiências motoras, por meio de objetivos e conteúdos sequenciados e progressivos, bem como o aprofundamento dos conceitos de atividade física, exercício físico, aptidão física e saúde nos adolescentes (COSTA; GARCIA; NAHAS, 2012).

A educação física escolar, neste sentido, está sendo utilizada com utilidade biológica. Contribuindo com o indivíduo somente pela busca das suas determinações e meios vitais, ou seja, compreendendo o indivíduo apenas como um organismo biológico. Saviani (2012b), ao afirmar que a educação do indivíduo direcionada exclusivamente para a utilidade biológica, expõe que ela não estabelece uma validade essencial para o desenvolvimento integral do indivíduo. No caso, a educação física escolar a serviço das ciências naturais, está atuando apenas no sentido de conformar o indivíduo no seu ambiente e, por conseguinte, a encontrar formas para continuar se adaptando a ele.

Em contrapartida, no que se refere às orientações para a educação física escolar pelas ciências humanas, observa-se um aumento da diversidade de proposições pedagógicas. Todavia, em acordo com Bracht (1999, p. 78), “[...] embora a prática pedagógica ainda resista a mudanças, ou seja, a prática acontece ainda balizada pelo paradigma da aptidão física e esportiva, várias propostas pedagógicas foram gestadas nas últimas duas décadas e se colocam hoje como alternativas".

Estas proposições norteiam-se basicamente pelas especificidades das ciências humanas e, portanto, a prática pedagógica assume as demandas preconizadas por tais ciências. Com efeito, há um avanço no que dispõem as diretrizes pedagógicas para o trabalho educativo na 
educação física escolar, pois se amplia a compreensão sobre esta área do conhecimento na sua relação com a realidade concreta e suas contradições. Assim, permite encontrar um novo horizonte que tenha condições de perspectivar e, por consequência, concretizar a educação física escolar como elemento fundamental para a formação integral do aluno. Dito de outra maneira, preconiza uma formação que dê condições de o aluno historicizar a situação social hodierna e, a partir disso, concretizar intervenções transformadoras no contexto social.

Entretanto, do ponto de vista pedagógico, o problema disposto perante as ciências naturais continua de maneira predominante, perante as ciências humanas, pois a educação física escolar continua sendo o ponto de passagem para estas ciências. Esta, que se torna somente um fato antropológico, sociológico ou psicológico.

Saviani (2012a), ao realizar esta análise no âmbito da educação, afirma que há um circuito da educação, no qual os pontos de início e de chegada do processo educativoestão externos à educação.

Assim, as pesquisas no âmbito das ciências da educação (sociologia da educação, psicologia da educação, economia da educação, antropologia educacional, biologia educacional etc.) circunscrevem a educação como seu objeto, encarando-a como fato sociológico ou psicológico ou econômico etc., que é visto, consequentemente, à luz das teorizações sociológicas, psicológicas etc., a partir de cuja estrutura conceptual são mobilizadas as hipóteses explicativas do aludido fato. O processo educativo é encarado, pois, como campo de teste das hipóteses que, uma vez verificadas, redundarão no enriquecimento do acervo teórico da disciplina sociológica (psicológica, econômica etc.) referida (SAVIANI, 2012a, p. 121).

Nota-se que processo equivalente ocorre com a educação física escolar. Estão em vigência, neste constructo, dois importantes problemas (no caso das ciências humanas): a) continua o deslocamento da essência, propriamente dita, da educação física escolar e, no entanto, agora sua natureza é compreendida como um objeto de distintas ciências humanas; b) há predomínio da visão culturalista sobre a educação física escolar, sendo um objeto destas ciências. 
Quanto ao primeiro problema, Sánchez Gamboa (2007) identifica que a educação física está flutuando entre outras ciências. $\mathrm{O}$ autor salienta que a educação física e, em nosso caso, a educação física escolar, "[...] sofre as flutuações do denominado 'colonialismo epistemológico' das ciências mães” (SÁNCHEZ GAMBOA, 2007, p. 26). A educação física escolar “[...] torna-se um campo colonizado onde são aplicados métodos e as teorias dessas ciências-mãe, denominando-se, por exemplo, Psicologia da Aprendizagem Motora, Sociologia do esporte, Fisiologia do esforço etc." (SÁNCHEZ GAMBOA, 2007, p. 26). Portanto, tanto no âmbito das flutuações da educação física escolar nas ciências naturais, como nas ciências humanas, "[...] expressam o circuito simples do saber. O ponto de partida e o ponto de chegada são as teorias sociológicas, psicológicas, fisiológicas e não a Educação Física, que funciona como ponto de passagem" (SÁNCHEZ GAMBOA, 2007, p. 26).

Neste sentido, seguindo a reflexão de Sánchez Gamboa (2007), o ponto de partida está nos referenciais teóricos de determinadas ciências humanas já constituídas, e passam a ser utilizados nos fenômenos específicos da educação física escolar, cujo intuito é, primeiro, explicar tais fenômenos e, por consequência, voltar para a base teórica, confirmando ou não suas hipóteses. "Estabelece-se assim um circuito em que os fenômenos da Educação Física são pontos de passagens das elaborações científicas, caracterizando um processo de 'colonialismo epistemológico' sobre um campo aberto a diversas apropriações” (SÁNCHEZ GAMBOA, 2007, p. 26-27).

Podemos verificar este processo evidenciando, por exemplo, a análise de Daolio (2007) sobre o uso recorrente do termo cultura na esfera da educação física escolar. Ele aponta que, como o termo cultura aparece de distintas maneiras e sem, necessariamente, as devidas explicações conceituais e históricas, ocorre um uso reducionista e superficial de tal termo. Com isto, o autor propôs-se a realizar uma análise crítica sobre o uso demasiado do termo. Contudo, para tal análise, o autor recorre aos preceitos científicos da antropologia social.

Ora, o que Daolio (2007) se propôs nada mais foi do que analisar a utilização do termo cultura (a partir de distintas ciências humanas) utilizando, também, uma determinada ciência humana, a antropologia social. A 
problemática permanece a mesma, ou seja, o colonialismo epistemológico permanece, uma vez que a educação física escolar está sendo compreendida como um objeto de uma determinada ramificação, neste caso, da antropologia social.

Quanto ao segundo problema, estabelece, via diversas vertentes no campo da educação física escolar, que a reduz somente à cultura. Compreende a educação física escolar como objeto de determinadas ciências humanas que, por sua vez, são compreendidas por meio de uma doutrinação onde a cultura assume posição cabal, isto é, assume o advento de um culturalismo. De acordo com Abbagnano (2007, p. 265), culturalismo trata-se de "[...] toda doutrina antropológica, filosófica, psicológica, etc. que atribua papel primordial à cultura [...]".

Em epítome, podemos constatar o paradoxo da prática pedagógica em educação física escolar: há respostas plausíveis e coerentes sobre a problemática pedagógica da educação física escolar; no entanto, apresentam conclusões contrárias, ou seja, definições opostas. Destarte, concluímos que o paradoxo da educação física escolar se constitui em um impasse, em virtude da polaridade estabelecida entre as ciências naturais e humanas, afirmando a educação física escolar apenas como um objeto ou um fator (uma ramificação).

Eis a necessidade de buscar delineamentos que possam superar este paradoxo. Isto porque tal paradoxo surge de uma aporia, isto é, de um “[...] 'nexo de pensamento ainda em formação, pleno de contradições que esperam uma solução”' (GRAMSCI apud FORENZA, 2017, p. 46).

Continuando assentados na leitura de Forenza da visão de Gramsci, compreendemos que tais paradoxos (epistemológico e pedagógico no campo da educação física escolar) é síntese de uma ainda inexistência, ou seja, síntese da "[...] ausência de solução apenas como fase transitória e efêmera no âmbito da evolução de um 'pensamento em desenvolvimento', ainda em formação" (FORENZA, 2017, p. 46).

Visando contribuir com esse pensamento em desenvolvimento, isto é, na tentativa de superar o paradoxo vigente na educação física escolar, passamos para o próximo momento, cuja tentativa ocorreu na perspectiva de apresentar, em linhas gerais, possíveis apontamentos que elucidem a condição concreta para a superação destes dilemas contraditórios. 


\section{Possíveis apontamentos para a superação dos atuais dilemas contraditórios na educação física escolar}

Ilustrada a questão do paradoxo da educação física escolar e as condições objetivas para que este paradoxo se legitime, passamos a tentar apresentar indicativos, de maneira ampla, para sanar a condição dúbia que impera nas pesquisas e discussões sobre a educação física escolar.

Voltemos ao destaque que realizamos sobre o posicionamento de Saviani (2012a) acerca dos circuitos da educação. O circuito da educação, mencionado em momento anterior do presente texto, representa um grupo, o qual contempla as ciências que, historicamente, se validaram por estabelecer um objeto de estudo que é externo à educação e que, no seu interior, constituiu ramificações específicas que tornam a educação como seu próprio objeto, "[...] recortando, no conjunto do fenômeno educativo, aquela faceta que the corresponde" (SAVIANI, 2012a, p. 121).

Não à toa que, no caso da educação física escolar, ocorre situação similar, pois não estamos tratando de outra coisa senão uma modalidade de educação, ou seja, um tipo determinado de educação escolar. Logo, como na educação escolar, é comum pensar este circuito também para a educação física escolar. Efetiva, na amplitude do fenômeno educativo específico da educação física, a seleção de elementos que correspondem a determinadas facetas de tais ciências.

Todavia, como condição cabal para a superação deste impasse estabelecido, é compreendê-la por meio de um circuito inverso ao supracitado. Este circuito, parte de uma ciência da educação (propriamente dita), "[...] se constituiria na medida em que constituísse a educação, considerada em concreto, isto é, em sua totalidade, como seu objeto" (SAVIANI, 2012a, p. 121).

Por consequência, a educação assume função primordial desde o ponto de partida até o ponto de chegada do processo educativo escolar. Observemos:

Em vez de se considerar a educação a partir de critérios sociológicos, psicológicos, econômicos etc., são as contribuições das diferentes 
áreas que serão avaliadas a partir da problemática educacional. O processo educativo erige-se, assim, em critério, o que significa dizer que a incorporação desse ou daquele aspecto do acervo teórico que compõe o conhecimento científico em geral dependerá da natureza das questões postas pelo próprio processo educativo (SAVIANI, 2012a, p. 121).

A possibilidade de superação do paradoxo da educação física (como uma modalidade de educação) se concretiza se for compreendida por meio desta última acepção sobre o circuito da educação. Com efeito, trata-se de compreender a educação física escolar por uma ciência da educação propriamente dita, isto é, que seja autônoma e unificada.

Autônoma, pois seu objeto primordial é a prática pedagógica e, portanto, seu ponto de partida e de chegada é a prática pedagógica, assumindo as demandas oriundas dos problemas de cunho pedagógico. E unificada, pois a incorporação de certos aspectos da composição teórica de determinados conhecimentos científicos (determinadas ciências) urgirá, dependendo das demandas surgidas na natureza das questões evidenciadas no bojo da própria prática pedagógica, no interior da relação professor-aluno, nas problemáticas oriundas do processo pedagógico de ensino, aprendizagem e desenvolvimento do aluno.

Deste modo, consubstancia-se a condição concreta de superação do paradoxo da educação física, isto é, a sua fase de colonialismo epistemológico. Segundo Sánchez Gamboa (2007, p. 27),

Isso implica a articulação de um campo interdisciplinar que tem como eixo, a natureza e a especificidade da Educação Física que articula a contribuição das várias teorias científica (sic.), e elabora explicações e compreensões mais ricas e complexas na medida em que tece, em torno de fenômenos concretos, interpretações tencionadas por um eixo central [...].

A prática pedagógica em educação física passa, em suma, a ser o ponto fundamental no contexto escolar. As demandas surgem do problema emergido na esfera pedagógica, em outras palavras, basicamente, na relação entre professor e aluno no que tange à transmissão e apropriação do 
conhecimento historicamente sistematizado. Tanto as distintas ciências naturais como as inúmeras ciências humanas passam a efetivar função inversa no bojo da prática pedagógica, uma vez que se tornam instrumentos, por meio do acervo teórico que compõe as suas especificidades científicas, para as demandas do processo de ensino, aprendizagem e desenvolvimento do aluno.

Com efeito, a psicologia, por exemplo, pode contribuir para a formação do professor, no que se refere a compreender a periodização do desenvolvimento psíquico do aluno, bem como as atividades dominantes em cada período de seu desenvolvimento. Da mesma forma que o acervo teórico que consubstancia o conhecimento científico específico da fisiologia pode se tornar um instrumento pedagógico para elucidar a problemática de como ocorrem, por exemplo, os processos físico-químicos do aluno na sua relação com a realização de uma determinada prática corporal. Nota-se que não é a educação física escolar um objeto específico de certo ramo da psicologia ou da fisiologia que direciona o trabalho educativo. É a transmissão do conhecimento sistematizado, por meio de formas didático-metodológicas adequadas para a apropriação de tal conhecimento que orientam o trabalho educativo, sendo os acervos teóricos, no caso do exemplo supradito da psicologia e da fisiologia, que serão submetidos ao crivo da prática pedagógica.

A condição sine qua non para a superação do paradoxo estabelecido no campo da educação física escolar é a mesma a ser compreendida a partir de uma ciência da e para a educação, isto é, em um sentido autônomo e unificado. Dito de outro modo, é necessário que a educação física escolar esteja submetida à fundamentação de uma teoria da educação. Afinal, não estamos apontando outra coisa senão a educação física escolar como uma modalidade de educação, mais precisamente uma modalidade de educação escolar. É necessário, por conseguinte, que esteja apoiada em uma tríade que se configura na relação recíproca entre filosofia da educação, teoria educacional e prática pedagógica.

Este é o caminho que possibilitará condições de resolver o vigente paradoxo da educação física no campo escolar e, por consequência, superar as atuais perspectivas contraditórias existentes. 


\section{Considerações finais}

Pudemos averiguar que há, de fato, um paradoxo da educação física na esfera escolar. Este paradoxo se estabelece a partir de duas questões fundamentais para legitimar a função social de uma determinada área do conhecimento e, neste caso, um componente curricular da escola.

A primeira questão está relacionada com o paradoxo da educação física, instituído por perspectivas contrárias de cunho epistemológico. Preconizam-se as expectativas contrárias para a educação física escolar entre as ciências naturais e humanas, onde se instituem diferentes maneiras de compreender aquilo que é a natureza da educação física escolar.

Como consequência deste primeiro paradoxo, surge o segundo, cuja questão aloca-se nas perspectivas contrárias sobre a especificidade da educação física escolar, isto é, o trabalho educativo (a prática pedagógica). Tais perspectivas contrárias também sofrem influências dos posicionamentos contraditórios entre ciências naturais e humanas, sobre as demandas específicas da prática pedagógica em educação física.

Como possível saída para este paradoxo, propomos que a educação física escolar, como modalidade de educação, esteja submetida aos preceitos de uma teoria da educação, ou seja, uma ciência da e para a educação, cuja condição específica é a prática pedagógica como ponto de partida e de chegada do processo educativo escolar.

Entretanto, para que tal condição se concretize, é necessário aprofundar a presente temática e ampliar as reflexões sobre como poderá objetivar a natureza da educação física escolar no âmbito das diretrizes de uma teoria da educação que, a nosso ver, deve estar consubstanciada na tríade supradita, a partir de uma concepção de mundo e, por conseguinte, de educação transformadora. 


\section{Referências}

ABBAGNANO, N. Dicionário de filosofia. 5. ed. rev. ampl. São Paulo: Martins Fontes, 2007.

BRACHT, V. A constituição das teorias pedagógicas da educação física. Cadernos CEDES, Campinas, ano XIX, n. 48, p. 69-88, ago. 1999.

BRACHT, V. Cultura corporal, cultura de movimento ou cultura corporal de movimento? In: SOUZA JUNIOR, M. (Org.). Educação física escolar: teoria e política curricular, saberes escolares e proposta pedagógica. 2. ed. Recife: EDUPE, 2011. p. 99-112. COLETIVO DE AUTORES. Metodologia do ensino de educação física. 2. ed. rev. 3. reimpr. São Paulo: Cortez, 2014.

COSTA, F. F.; GARCIA, L. M. T.; NAHAS, M. V. A educação física no Brasil em transição: perspectivas para a promoção da atividade física. Revista Brasileira de Atividade Física e Saúde, Pelotas, v. 17, n. 1, p. 14-21, fev. 2012.

DAOLIO, J. Educação física e o conceito de cultura. 2. ed. Campinas: Autores Associados, 2007.

FERREIRA, A. B. H. Mini Aurélio: o dicionário da língua portuguesa. 8. ed. rev. atual. reimpr. Curitiba: Positivo, 2014.

FORENZA, E. Aporia. In: LIGUORI, G.; VOZA, P. (Orgs.). Dicionário gramsciano (1926-1937). São Paulo: Boitempo, 2017. p. 46.

GUEDES, D. P. Educação para a saúde mediante programas de educação física escolar. Motriz: Revista de Educação Física, Rio Claro, v. 05, n. 01, s.p., jun. 1999.

GUEDES, D. P.; GUEDES, J. E. R. P. Esforços físicos nos programas de educação física escolar. Revista Paulista de Educação Física, São Paulo, v. 15, n. 01, p. 33-44, jan./jun. 2001. 
HUNGARO, E. M. A educação física e a tentativa de "deixar de mentir": o projeto de "intenção de ruptura". In: MEDINA, J. P. S. A educação física cuida do corpo e "mente": novas contradições e desafios do século XXI. 26. ed. 2. reimpr. Campinas: Papirus, 2014. p. 135-159.

LAZZAROTTI FILHO, A. et al. O termo práticas corporais na literatura científica brasileira e sua repercussão no campo da educação física. Revista Movimento, Porto Alegre, v. 16, n. 1, p. 11-29, jan./mar. 2010.

NAHAS, M. V. Atividade física, saúde e qualidade de vida: conceitos e sugestões para um estilo de vida ativo. 6. ed. rev. Londrina: Mimeograf, 2013.

SÁNCHEZ GAMBOA, S. Epistemologia da educação física: as inter-relações necessárias. Maceió: EDUFAL, 2007.

SAVIANI, D. O paradoxo da educação escolar: uma análise crítica das expectativas contraditórias depositadas na escola. In: SAVIANI, D. O lunar de sepé: paixão, dilemas e perspectivas na educação. Campinas: Autores Associados, 2014.

SAVIANI, D. Educação brasileira: estrutura e sistema. 11. ed. rev. Campinas: Autores Associados, 2012b.

SAVIANI, D. A pedagogia no Brasil: história e teoria. 2. ed. Campinas: Autores Associados, 2012a.

Recebido: 30/09/2018

Received: 09/30/2018

Recibido: 30/09/2018

Aprovado: 24/10/2018 Approved: 10/24/2018 Aprobado: 24/10/2018 